\title{
Comparing Corn Stover and Switchgrass Biochar: Characterization and Sorption Properties
}

\author{
Steven C. Peterson ${ }^{1}$, Michael Appell ${ }^{2}$, Michael A. Jackson ${ }^{3}$, Akwasi A. Boateng ${ }^{4}$ \\ ${ }^{1}$ Plant Polymer Research, National Center for Agricultural Utilization Research, United States Department of \\ Agriculture, Peoria, IL, USA \\ ${ }^{2}$ Bacterial Foodborne Pathogens \& Mycology Research, National Center for Agricultural Utilization Research, \\ United States Department of Agriculture, Peoria, IL, USA \\ ${ }^{3}$ Renewable Product Technology, National Center for Agricultural Utilization Research, United States \\ Department of Agriculture, Peoria, IL, USA \\ ${ }^{4}$ Sustainable Biofuels \& Coproducts, Eastern Regional Research Center, United States Department of Agriculture, \\ Wyndmoor, PA, USA \\ Correspondence: Steven C. Peterson, Plant Polymer Research, National Center for Agricultural Utilization \\ Research, United States Department of Agriculture, Peoria, IL, USA. Tel: 1-309-681-6325. E-mail: \\ Steve.Peterson@ars.usda.gov
}

Received: September 6, 2012 Accepted: October 9, 2012 Online Published: December 13, 2012

doi:10.5539/jas.v5n1p1 URL: http://dx.doi.org/10.5539/jas.v5n1p1

Mention of companies and/or trade names are necessary to report factually on available data; however, the USDA neither guarantees nor warrants the standard of the product, and the use of the name by the USDA implies no approval of the product to the exclusion of others that may also be suitable

\begin{abstract}
A switchgrass biochar (SB) produced by fast pyrolysis and a corn stover biochar (CSB) from a slow pyrolysis process were mechanically milled and characterized. Both of these biochars are very cost-effective and originate as residues from bioenergy production and the corn industry, respectively. These two biochars were evaluated for their sorptive properties with both water and the estrogen containing compounds estrone, $\beta$-estradiol, and zearalenone via batch rebinding assays in salt solutions. Although CSB had greater total surface area than SB, SB was a more porous biochar, indicated by its greater micropore surface area. For both water and all estrogen containing compounds, SB had better sorptive capability, most likely due to its higher micropore surface area. These results suggest ball milled biochars from switchgrass and corn stover offer promise for a sustainable approach to removing toxins from water.
\end{abstract}

Key words: biochar, estradiol, estrone, isotherm, micropore surface area, zearalenone

\section{Introduction}

Biochar is the term for the solid residue left behind during the pyrolytic decomposition of any organic feedstock. For many years biochar has been used primarily for the purposes of carbon sequestration (Jha, Biswas, Lakaria, \& Rao, 2010) and to improve soil fertility (Masulili, Utomo, \& Syechfani, 2010; McHenry, 2011; Widowati, Utomo, Guritno, \& Soehono, 2012). Biochar is comprised of essentially carbon and ash, although the specific composition varies greatly depending on the feedstock and processing conditions of the pyrolysis reaction (Novak et al., 2009). Pyrolysis is generally categorized by the length of time that the feedstock is heated; "fast" pyrolysis typically happens on the order of seconds (heating rates $\geq 1000 \mathrm{~K} /$ minute), and this condition maximizes the generation of bio-oil. "Slow" pyrolysis usually takes at least 30 minutes to several hours (heating rates $\leq 100 \mathrm{~K} /$ minute) for the feedstock to fully pyrolyze, and yields more biochar and gas, but less bio-oil (Brown, Wright, \& Brown, 2011). Most large-scale pyrolysis research and the resulting reactors have been geared towards bioenergy production; more specifically, bio-oil fuel intermediates and chemicals so that renewable sources of energy to replace fossil fuels can be developed (Laird, Brown, Amonette, \& Lehmann, 2009; Lee, Hawkins, Day, \& Reicosky, 2010). Large-scale slow pyrolysis methods, on the other hand, are not as prevalent in industry, presumably since slow pyrolysis favors the (perceived) less valuable production of solid char and small amounts of syngas as opposed to 
bio-oil. Because of this biochar from slow pyrolysis processes has not been investigated to the same extent as biochar from fast pyrolysis processes. However, if profitable uses for biochar arose, slow pyrolysis may become more prevalent since this method produces higher biochar yields.

In this study we have chosen two biochars to compare that will be popular for years to come based on their availability and the current bioenergy industry. The first is a corn stover biochar (CSB) produced by a slow pyrolysis process. Corn stover, by a large margin, makes up the largest quantity of biomass residue in North America (a conservative estimate is approximately 75 million tons per year) (Perlack et al., 2005). As crop residue it is a very low value commodity and additional ways to utilize these material profit farmers. Production of corn stover biochar using slow pyrolysis can also provide heat that can further be used to offset costs. The second biochar we have chosen to study is a common byproduct of the bioenergy industry, switchgrass biochar (SB). Switchgrass has a fast growth rate, low energy input per acre, and is very sustainable. Switchgrass is already one of the most common feedstocks for bio-oil production, and much progress has been made in all aspects of bioenergy production, including field-validated biomass production plans for the Midwestern and Central plains of North America (Mitchell, Vogel, \& Uden, 2012; Vogel, Sarath, Saathoff, \& Mitchell, 2011).

One potential way to add value to biochar is to use it as sorptive media for toxic materials. Biochar has been shown to be an effective sorbent for toxic compounds such as heavy metals (Beesley, Moreno-Jiménez, \& Gomez-Eyles, 2010; Mohan et al., 2007) and pesticides (Zheng, Guo, Chow, Bennett, \& Rajagopalan, 2010). Demonstrating that biochar can remove additional types of materials would increase its value. Recently, endocrine disrupting chemicals (EDCs) have been popular in toxicology research since these compounds cause sexual aberrations in fish and other wildlife at very low concentrations; although definitive concentration limits are still being debated, it is clear that adverse effects begin to show themselves at nanomolar concentration levels (Basile et al., 2011). EDCs come from three different classes of compounds; pharmaceuticals, personal care products, and pesticides. Of the pharmaceuticals, natural and synthetic estrogen-containing compounds such as estrone and estradiol make up a large percentage of the EDCs in wastewater because of their popularity in menopause treatment and fertility control (Whitehead \& Rice, 2006). Sarmah and coworkers (2010) successfully used biochars as soil amendments that had high sorptive capacity for EDCs. Their research suggested that high surface area, high carbon content, low ash content, and the presence of polar functional groups such as $-\mathrm{OH}$ and $\mathrm{C}=\mathrm{O}$ promoted better sorptive capacity for EDCs.

In this study, CSB and SB were fully characterized in terms of their elemental, physical properties, and sorptive properties with both water and the EDCs estrone (E1), $\beta$ - estradiol (E2), and zearalenone (ZEN, a potent estrogenic mycotoxin) in water. SB was made from a fast pyrolysis method as a byproduct from bio-oil, and CSB was made from a slow pyrolysis method where the biochar was the intended product (for soil carbon sequestration). The biochars studied show favorable commercial potential as adsorptive media because they are renewable materials that are easily processed and need no chemical activation to bind to the EDCs.

\section{Materials}

CSB was from corn stover feedstock that was pyrolyzed at $600^{\circ} \mathrm{C}$ for approximately 45 minutes in a slow-pyrolysis scheme that favored high char yield. SB was made from switchgrass feedstock in a fast-pyrolysis reactor optimized for bio-oil production $\left(480^{\circ} \mathrm{C}\right.$, pyrolyzing the switchgrass at a rate of $2.22 \mathrm{~kg} / \mathrm{hr}$, residence time for carbonization < 10 s) (Boateng, Daugaard, Goldberg, \& Hicks, 2007).

E1, E2, ZEN, and $\mathrm{CaCl}_{2}$ were purchased from Sigma-Aldrich (St. Louis, USA). Hydrochloric acid was purchased from Fisher Scientific (Pittsburgh, USA). Acetonitrile and methanol were purchased from EMB (Gibbstown, USA). Deionized water was used in the preparation of all reagents (Nanopure II, Sybron/Barnstead). All solvents were HPLC grade. The standard stock solution was prepared by dissolving $1 \mathrm{mg}$ of estrogen in $1 \mathrm{~mL}$ of solvent (E1 in acetontrile, E2 in methanol, and ZEN in 1:1 acetonitrile/water).

\section{Methods}

Biochar was ball milled in an SFM-1 (model QM-3SP2) planetary ball mill (MTI Corporation, Richmond, CA) using $500 \mathrm{~mL}$ capacity stainless steel milling jars and lids. Milling media consisted of $3 \mathrm{~mm}$ diameter YSZ spheres (Inframat Corporation, Manchester, CT) at a weight ratio of 200:1 milling media:biochar. Samples were milled for a total of 6 hours at $500 \mathrm{rpm}$, reversing rotation direction after 3 hours.

Elemental composition data were obtained using a Thermo Flash EA1112 CHNS/O analyzer, by complete combustion of the biochars followed by GC quantification of the combustion products. Ash was determined by heating the sample in a muffle furnace to $650^{\circ} \mathrm{C}$ for 6 hours. Ash content was calculated as the percentage remaining, and oxygen was determined by difference between the sample and sum of $\mathrm{C}, \mathrm{H}, \mathrm{N}$, and ash. 
Surface analyses were performed on a Quantachrome ASiQ (Quantachrome Instruments, Boynton Beach, FL). Samples were degassed at $200^{\circ} \mathrm{C}$ for $10 \mathrm{~h}$ prior to analysis. Surface areas were determined at $-196^{\circ} \mathrm{C}$ using $\mathrm{N}_{2}$ as the adsorbate in a relative pressure range of 0.025-0.30 using the Brunauer-Emmett-Teller (BET) method for total surface area calculations. The pressure range used in the calculation for each sample was chosen based on the best linear fit for points in the $0.025-0.30 \mathrm{P} / \mathrm{P}_{0}$ range. Micropore surface areas were calculated using the $\mathrm{t}$-method (Lippens \& de Boer, 1965) in the relative pressure range of 0.15-0.30.

For scanning electron microscopy (SEM), the biochar powders were mounted onto aluminum stubs with conductive carbon tape. The specimens were then sputter coated with Au-Pd and examined with a JEOL $6400 \mathrm{~V}$ (JEOL USA, Inc., Peabody, MA) scanning electron microscope.

FTIR spectra were collected using a single bounce Durascope (Sens IR) ATR in a Thermo Nicolet Avatar 370 spectrometer. Peaks were determined manually after obtaining the absorbance values.

Water sorption of the samples as a function of relative humidity was measured using a Q5000 SA (TA Instruments, New Castle, DE, USA). The sample was initially dried in the atmospheric chamber until humidity plateaued near zero, then it was cycled from 0 to $90 \%$ relative humidity and then back to $0 \%$ humidity again so that both water sorption and water holding behavior could be observed.

EDC sorption of the biochars was investigated by batch rebinding assays carried out in $10 \mathrm{mM} \mathrm{CaCl}_{2}$ solutions ( $\mathrm{pH}$ 6.5). Various concentrations ( 0.5 to $1 \mu \mathrm{g} \mathrm{mL}^{-1}$ ) of estrogens were incubated with biochar ( $1 \mathrm{mg}$ ) dispersed in 40 $\mathrm{mL}$ of deionized water in a $50 \mathrm{~mL}$ centrifuge tube. Each experiment was shaken on a Lab-line Multi-wrist shaker at room temperature for $8 \mathrm{~h}$. The samples were centrifuged at $2000 \mathrm{rpm}$ for $10 \mathrm{~min}$. The supernatant $(1 \mathrm{~mL})$ was filtered through a $0.20 \mu \mathrm{m}$ filter (PTFE) and analyzed by LC-analysis. Experiments were performed in triplicate. The bound estrogens were calculated by subtracting the amount of estrogens free in solution at $8 \mathrm{~h}$ in presence of the biochar from standard solutions run without biochar.

The estrogen levels were determined by LC-analysis with UV detection on a photodiode array detector at 280 $\mathrm{nm}$ (E1 and E2), and fluorescence detection (ZEN, $\lambda_{\mathrm{ex}}=314 \mathrm{~nm}, \lambda_{\mathrm{em}}=460 \mathrm{~nm}$ ). The HPLC consisted of a Shimadzu LC-20AT pump, a Rheodyne 7725 manual injector with a $20 \mu \mathrm{L}$ injection loop, a SPD-M20A diode array detector, RA-10 fluorescence detector, a CBM-20A communication bus model, and a Phenomenex Luna 5 $\mu \mathrm{m} \mathrm{C} 18$ (2) 100A column $(250 \times 4.6 \mathrm{~mm})$. The mobile phase was 1:1 aceotnitrile:water. Levels were determined by calibration curves based on peak area between $0.02-1 \mu \mathrm{g} \mathrm{mL}-1$ (E1 $r^{2}=0.991,10.2 \mathrm{~min}$; E2 $r^{2}=0.995,7.2 \mathrm{~min}$; ZEN $r^{2}=0.989,12.3 \mathrm{~min}$ ).

\section{Results and Discussion}

\subsection{Elemental Composition and Surface Area}

The elemental composition and surface area data for both biochars are listed in Table 1. Both samples had similar carbon content. SB had almost twice the oxygen content as the CSB, consistent with observation that fast pyrolysis chars typically have higher oxygen concentration than slow pyrolysis char (Brewer, Schmidt-Rohr, Satrio, \& Brown, 2009). SB also had significantly lower ash content than CSB. Surface area data showed that although the total overall surface area was greater for the CSB, the SB had greater micropore surface area.

Table 1. Elemental and surface area results for the biochars studied

\begin{tabular}{lccccccc}
\hline $\begin{array}{l}\text { Biochar } \\
\text { sample }\end{array}$ & $\mathrm{C} \mathrm{( \% )}$ & $\mathrm{H}(\%)$ & $\mathrm{N}(\%)$ & $\mathrm{O}(\%)$ & Ash $(\%)$ & $\begin{array}{c}\text { Total surface } \\
\text { area }\left(\mathrm{m}^{2} / \mathrm{g}\right)\end{array}$ & $\begin{array}{c}\text { Micropore surface area } \\
\left(\mathrm{m}^{2} / \mathrm{g}\right)\end{array}$ \\
\hline CSB & 45.14 & 1.86 & 0.44 & 12.96 & 39.60 & 74 & 14 \\
SB & 43.65 & 3.71 & 0.78 & 24.99 & 26.87 & 46 & 23 \\
\hline
\end{tabular}



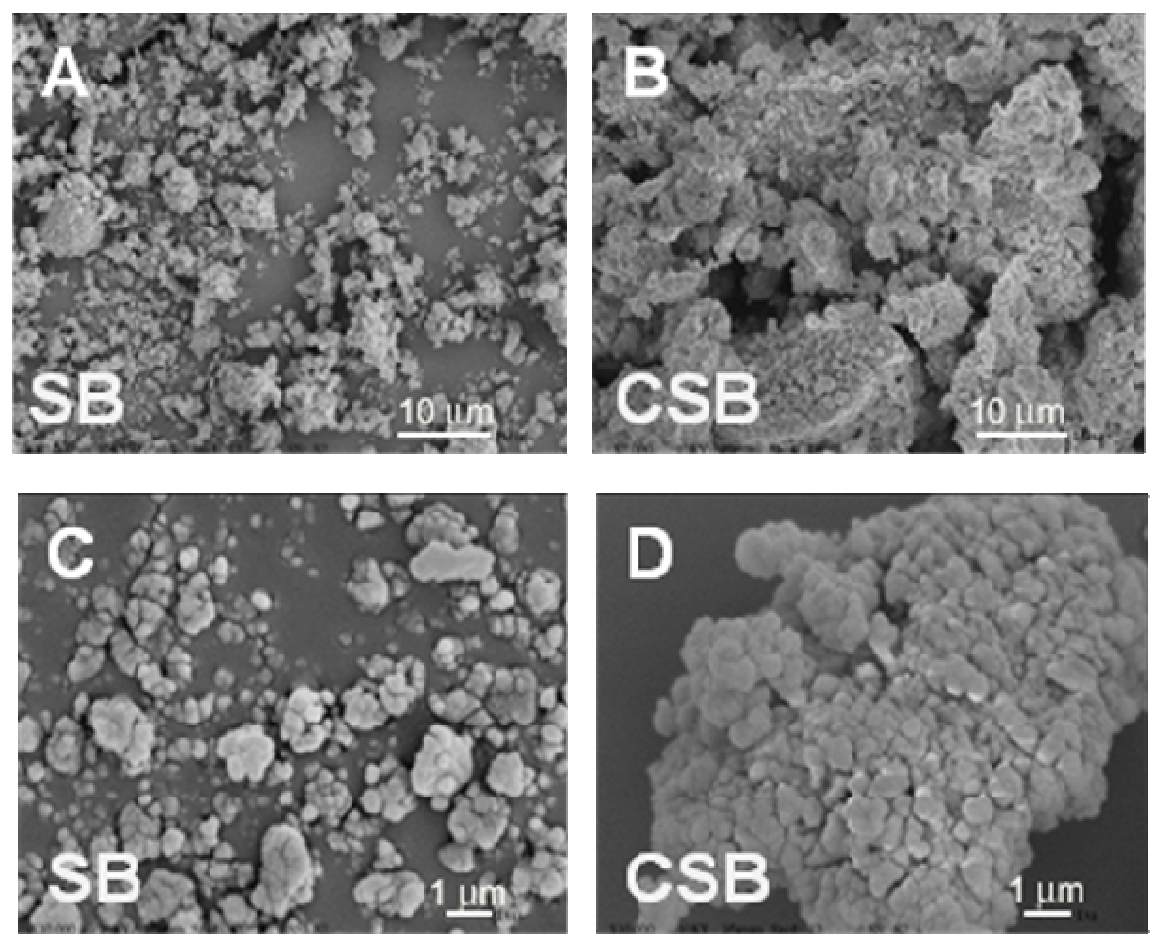

Figure 1. SEM images of SB and CSB

Figure 1 shows scanning electron microscope images of the two biochars. The SB had smaller particle size and was less agglomerated than the CSB. From higher magnification images $\mathrm{C}$ and $\mathrm{D}$, it can be seen that the smallest aggregates in each char are approximately the same size $(\sim 200 \mathrm{~nm})$, but secondary agglomerate structure is much more prevalent in the CSB. Biochars made via slow pyrolysis and/or lower temperatures typically will retain more of the inherent structural traits of the feedstock (Sarmah et al., 2010). A more thorough understanding of the feedstocks is in progress to help determine the relationship between feedstock properties and the resulting biochar. The tendency of CSB to agglomerate into larger particles than SB may ultimately decrease the number of available micropore sites so that EDCs can more effectively bind to SB.

\subsection{FTIR Spectra}

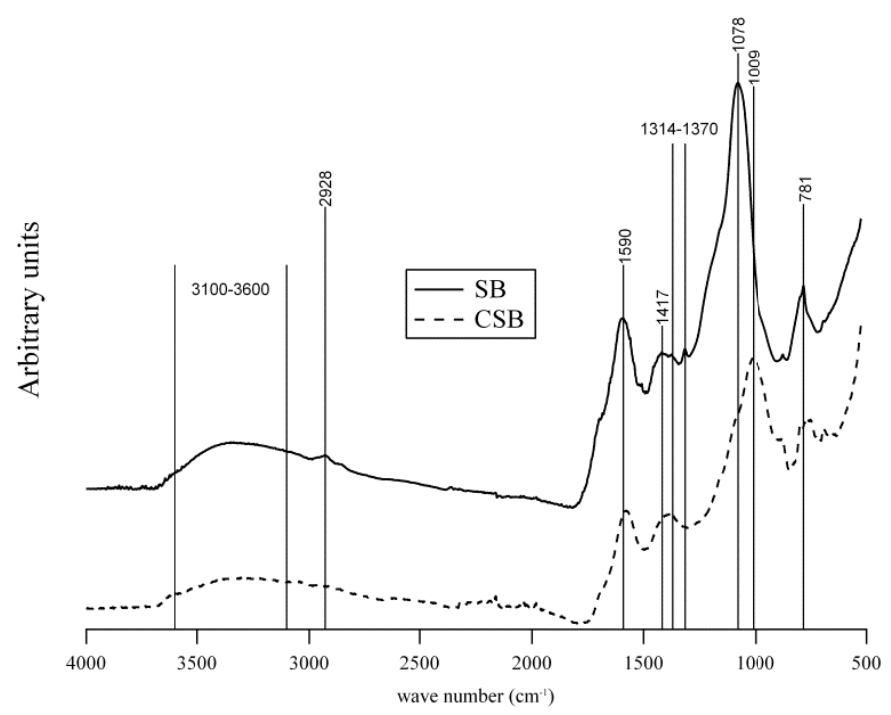

Figure 2. FTIR spectra of SB (solid line) and CSB (dashed). Wave numbers of interest are labeled 
Figure 2 shows FTIR spectra for the two biochars. The spectra were vertically shifted for clarity. The CSB spectrum was weaker in intensity than that of the SB, however it should be noted that since the biochar surface is heterogeneous, path lengths vary and intensities cannot be quantitatively compared. The spectra were similar for the two biochars, with the primary differences being a very small aliphatic C-H stretching peak at $2928 \mathrm{~cm}^{-1}$ that is present in the SB and not the CSB, and two differing peaks at $1078 \mathrm{~cm}^{-1}$ and $1009 \mathrm{~cm}^{-1}$. The former was present in the SB and was assigned to either a C-O-C pyranose ring skeletal vibration (Pastorova, Botto, Arisz, \& Boon, 1994), and/or the C-N stretch of an aliphatic primary amine. The latter appears at too low a wave number to be assigned to an amine, and most likely represents a P-O-R ester or phenyl phosphorus group (CRC Handbook CRC Handbook of Chemistry and Physics, 1990; Daasch \& Smith, 1951). These can be found in condensed phosphates present in fertilizers (Dick \& Tabatabai, 1987), which is likely with corn stover as the feedstock. The CSB spectrum has a very faint shoulder close to $1080 \mathrm{~cm}^{-1}$, and both biochars have peaks near $781 \mathrm{~cm}^{-1}$ and $1590 \mathrm{~cm}^{-1}$ that indicate the presence of amine. Referring to Table 1, SB had nitrogen content nearly twice that of the CSB, so this may be reflected qualitatively in the spectra here. Amine functional groups have been shown to have strong binding activity to ZEN (Urraca, Marazuela, Merino, Orellana, \& Moreno-Bondi, 2006), and should also bind E1 and E2, since all three are weak acids and capable of hydrogen bonding. The peaks near $1590 \mathrm{~cm}^{-1}$ may also represent aromatic $\mathrm{C}=\mathrm{C}$, common in biochar. Other notable peaks that were present in both biochars were the peaks from 1314-1370 $\mathrm{cm}^{-1}$, assigned to $\mathrm{C}-\mathrm{C}$ and $\mathrm{C}-\mathrm{O}$ skeletal vibrations, the $\mathrm{CH}_{2}$ bending peak at $1417 \mathrm{~cm}^{-1}$, and the O-H stretching peak from 3100-3600 $\mathrm{cm}^{-1}$ (Pastorova et al., 1994).

\subsection{Water Sorption}

The moisture content of SB and CSB is shown in Figure 3 as a function of relative humidity. During the entire cycle except for the highest humidity point $(90 \%)$, SB both absorbed and held more water vapor than CSB. This indicates that water is being absorbed into the micropore structure of the biochar, because although CSB has greater overall surface area than SB, SB has greater micropore surface area (Table 1). When water sorption data are viewed as a cycle, the vertical difference between each discrete relative humidity value indicates how well the biochar sample holds water. There is a notable sharp increase in moisture content for CSB from $80-90 \%$ relative humidity. This is most likely due to adsorption to the outer surface of the biochar; at $90 \%$ relative humidity, the CSB surpasses the SB briefly, but as the relative humidity is lowered, it releases moisture nearly as quickly as the surface of the biochar dries out with contact to the atmosphere. SB, on the other hand, is able to trap more water vapor in its micropores and thus retains moisture more effectively than the CSB.

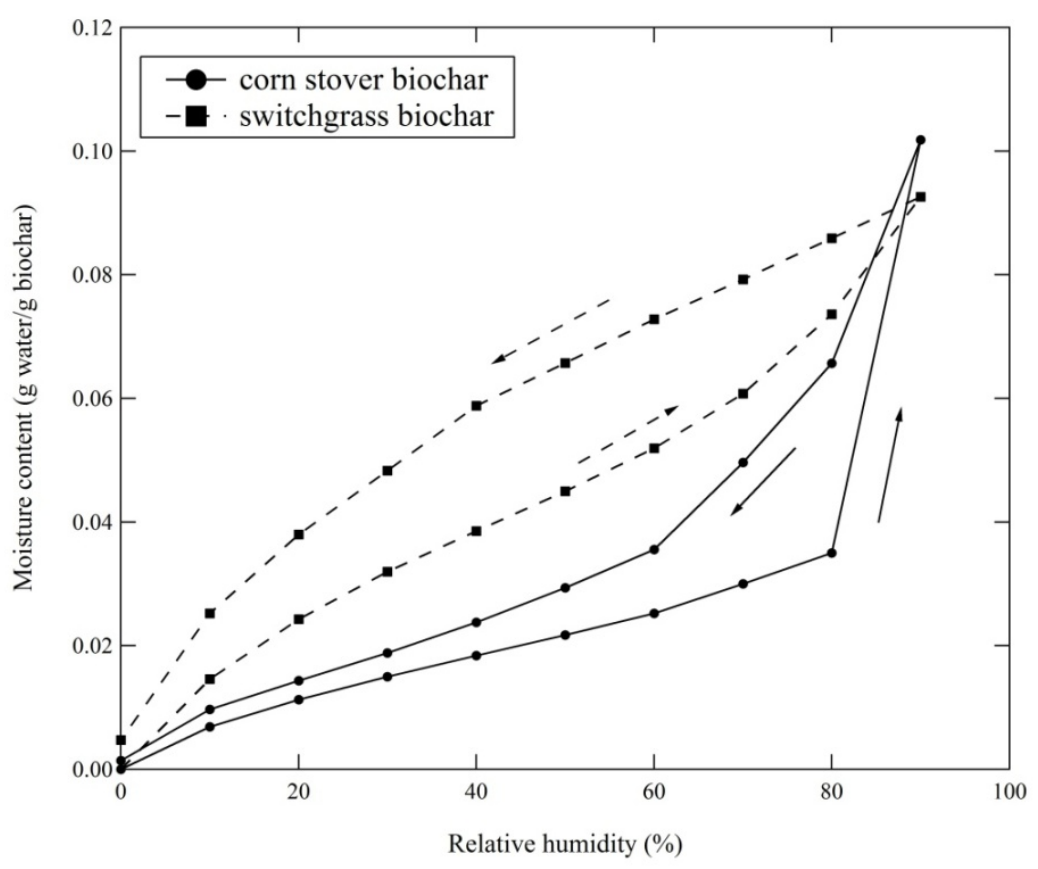

Figure 3. Moisture content of SB and CSB as a function of relative humidity. Arrows indicate the chronological order of the data collection; each sample went from $0 \%$ to $90 \%$ humidity and then back to $0 \%$ 


\subsection{EDC Sorption}

The ability of the biochars to remove EDCs from water was investigated by sorption isotherms. An $8 \mathrm{~h}$ incubation was sufficient to achieve equilibrium under the concentrations investigated. The heterogeneous Freundlich adsorption model has seen extensive use to characterize binding processes at equilibrium (Sun et al., 2011; Yoon, Westerhoff, Snyder, \& Esparza, 2003; Zheng et al., 2010).

The Freundlich equation is described as:

$$
q_{e}=K_{f} C_{e}^{1 / n}
$$

Where $K_{\mathrm{f}}$ is the Freundlich constant and $n$ is the heterogeneity index. $C_{e}$ is the concentration $\left(\mathrm{mg} \mathrm{L}^{-1}\right)$ of free estrogen at equilibrium, and $q_{\mathrm{e}}$ is the amount of bound estrogen $(\mathrm{mg})$ to the sorbent $(\mathrm{g})$. The constant $K_{\mathrm{f}}$ is associated with affinity and the sorptive capacity. The parameter $n$ provides information on the adsorption intensity and is associated with the favorability of the binding process. A value of $n$ is associated with the curvature of the isotherm ( $n=1$ is linear).

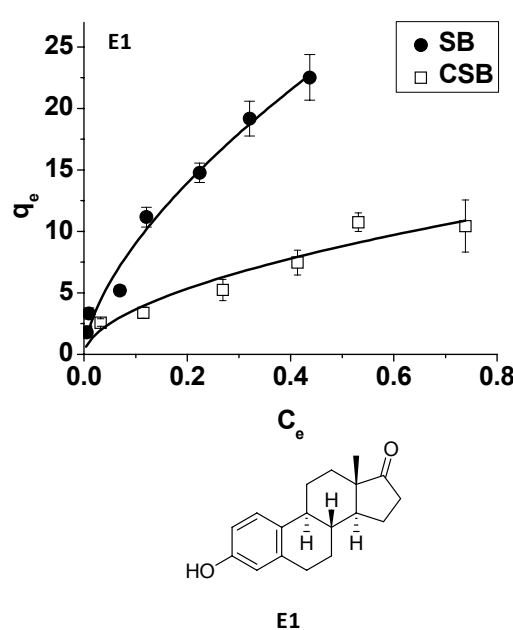

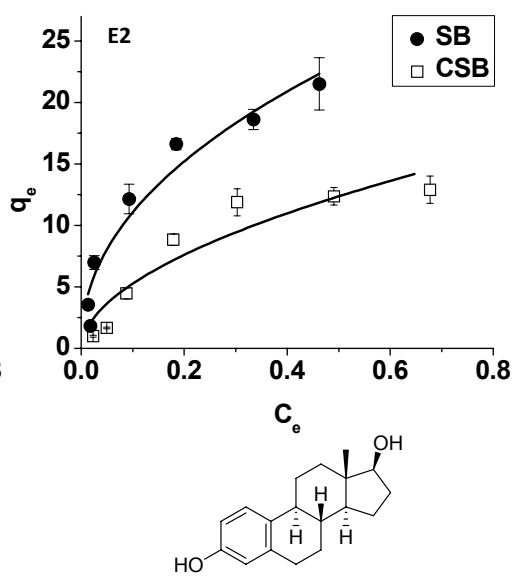

E2

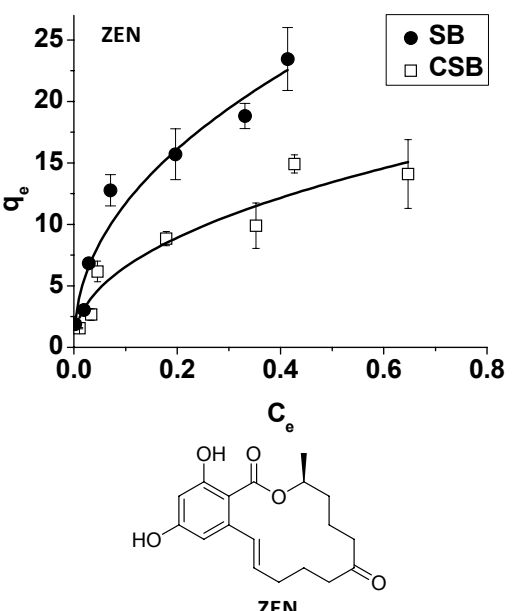

ZEN

Figure 4. Sorption isotherms for SB and CSB (1 mg) binding estrone (E1), $\beta$ - estradiol (E2), and zearalenone $(\mathrm{ZEN})$, in $10 \mathrm{mM} \mathrm{CaCl}_{2}(40 \mathrm{~mL})$

Table 2. Isotherm parameters obtained by fitting binding data with the Freundlich isotherms for the sorption of estrone, $\beta$-estradiol, and zearalenone on biochars in water

\begin{tabular}{lllll}
\hline Estrogen & Biochar & $K_{F}\left(\mathrm{mg} \mathrm{g}^{-1}\right)\left(\mathrm{L} \mathrm{mg}^{-1}\right)^{1 / n}$ & $1 / n$ & $R^{2}$ \\
\hline \multirow{2}{*}{ estrone } & CSB & $12.8 \pm 1.3$ & $0.54 \pm 0.11$ & 0.920 \\
& SB & $38.2 \pm 3.2$ & $0.63 \pm 0.06$ & 0.982 \\
$\beta$ - estradiol & CSB & $17.9 \pm 2.4$ & $0.53 \pm 0.11$ & 0.891 \\
& SB & $31.7 \pm 3.3$ & $0.46 \pm 0.07$ & 0.946 \\
\multirow{2}{*}{ zearalenone } & CSB & $18.3 \pm 2.0$ & $0.45 \pm 0.09$ & 0.912 \\
& SB & $33.9 \pm 3.5$ & $0.46 \pm 0.06$ & 0.957 \\
\hline
\end{tabular}

The sorption isotherm for E1, E2, and ZEN are provided in Figure 4 and the binding parameters are given in Table 2. Both biochars exhibit good sorptive properties for the estrogens in this study, and compare well with other popular sorptive media. The heterogeneity index, $1 / n$, of the estrogens in this study to bind to SB and CSB is within the range of values observed for E1 and E2 binding isotherms for activated carbon (Fukuhara, Iwasaki, Kawashima, Shinohara, \& Abe, 2006). Furthermore, the Freundlich parameter, $n$, suggests the binding of the certain estrogenic compounds to biochars occurs through a complex binding process, with multiple types of binding interactions. SB exhibits significantly greater sorptive capacity and adsorption intensity compared to CSB 
for the estrogens in this study. This trend may be related to the increase in micropore surface area associated with SB.

\section{Conclusions and Future Work}

Corn stover and switchgrass are two very affordable, renewable feedstocks from which to make biochar. Using biochar as a sorptive media to remove toxins or other undesirable components from water, food, or drug production adds value to these two surplus commodities. Both biochars were milled to increase surface area and had approximately the same carbon content. Neither biochar required any physical or chemical activation and thus provides an alternative sorbent to less sustainable materials. Sorption results for both water vapor and EDCs indicated that SB consistently had better sorption qualities compared to CSB. These results suggest that micropore surface area is a key factor in predicting sorptive quality of a given biochar, since the BET surface area of CSB was actually greater than SB, but SB had greater micropore surface area. A higher micropore surface area means that $\mathrm{SB}$ is more porous than $\mathrm{CSB}$ and is able to trap small particles (in this case water vapor and EDCs) to a greater extent.

Future work will involve looking into altering the pyrolysis processing method to see what factors could increase micropore surface area for these two feedstocks. Recent developments in so-called "top-lit updraft" (TLUD) processing techniques for producing biochar will also be explored since this method produces biochar with significantly lower ash content (less than 5\%) than the biochars produced in this study, and this may also improve sorptive quality by increasing the carbon/ash ratio.

\section{Acknowledgements}

The authors would like to thank Charles Mullen and Neil Goldberg for elemental analysis and other preparatory treatment of the biochar samples, Dr. Arthur Thompson for SEM imaging, A. J. Thomas for biochar processing and preparation, and Lijuan C. Wang for excellent technical assistance with the binding isotherms.

\section{References}

Basile, T., Petrella, A., Petrella, M., Boghetich, G., Petruzzelli, V., Colasuonno, S., \& Petruzzelli, D. (2011). Review of endocrine-disrupting-compound removal technologies in water and wastewater treatment plants: An EU perspective. Industrial \& Engineering Chemistry Research, 50(14), 8389-8401. http://dx.doi.org/10.1021/ie101919v

Beesley, L., Moreno-Jiménez, E., \& Gomez-Eyles, J. L. (2010). Effects of biochar and greenwaste compost amendments on mobility, bioavailability and toxicity of inorganic and organic contaminants in a $\begin{array}{llll}\text { multi-element polluted soil. Environmental Pollution, 158(6), 2282-2287. } & \text {. }\end{array}$ http://dx.doi.org/10.1016/j.envpol.2010.02.003

Boateng, A. A., Daugaard, D. E., Goldberg, N. M., \& Hicks, K. B. (2007). Bench-scale fluidized-bed pyrolysis of switchgrass for bio-oil production. Industrial \& Engineering Chemistry Research, 46(7), 1891-1897.

Brewer, C. E., Schmidt-Rohr, K., Satrio, J. A., \& Brown, R. C. (2009). Characterization of biochar from fast pyrolysis and gasification systems. Environmental Progress \& Sustainable Energy, 28(3), 386-396. http://dx.doi.org/10.1002/ep.10378

Brown, T. R., Wright, M. M., \& Brown, R. C. (2011). Estimating profitability of two biochar production scenarios: Slow pyrolysis vs fast pyrolysis. Biofuels, Bioproducts and Biorefining, 5(1), 54-68.

CRC Handbook of Chemistry and Physics. (1990). (71st edn). Boca Raton, FL, USA: CRC Press.

Daasch, L., \& Smith, D. (1951). Infrared Spectra of Phosphorus Compounds. Analytical Chemistry, 23(6), 853-868. http://dx.doi.org/10.1021/ac60054a008

Dick, R. P., \& Tabatabai, M. A. (1987). Polyphosphates as sources of phosphorus for plants. Fertilizer Research, 12(2), 107-118. http://dx.doi.org/10.1007/bf01048912

Fukuhara, T., Iwasaki, S., Kawashima, M., Shinohara, O., \& Abe, I. (2006). Adsorbability of estrone and 17ßestradiol in water onto activated carbon. Water Research, 40(2), 241-248. http://dx.doi.org/10.1016/j.watres.2005.10.042

Jha, P., Biswas, A. K., Lakaria, B. L., \& Rao, A. S. (2010). Biochar in agriculture - prospects and related implications. Current Science, 99(9), 1218-1225.

Laird, D. A., Brown, R. C., Amonette, J. E., \& Lehmann, J. (2009). Review of the pyrolysis platform for coproducing bio-oil and biochar. Biofuels, Bioproducts and Biorefining, 3(5), 547-562. http://dx.doi.org/10.1002/bbb.169 
Lee, J. W., Hawkins, B., Day, D. M., \& Reicosky, D. C. (2010). Sustainability: the capacity of smokeless biomass pyrolysis for energy production, global carbon capture and sequestration. Energy Environ. Sci., 3(11), 1695-1705. http://dx.doi.org/10.1039/c004561f

Lippens, B. C., \& de Boer, J. H. (1965). Studies on pore systems in catalysts V. The t method. Journal of Catalysis, $4(3), 319$.

Masulili, A., Utomo, W. H., \& Syechfani, M. S. (2010). Rice husk biochar for rice based cropping system in acid soil 1 . The characteristics of rice husk biochar and its influence on the properties of acid sulfate soils and rice growth in West Kalimantan, Indonesia. Journal of Agricultural Science, 2(1), 39-47.

McHenry, M. P. (2011). Soil Organic Carbon, Biochar, and Applicable Research Results for Increasing Farm Productivity under Australian Agricultural Conditions. Communications in Soil Science and Plant Analysis, 42(10), 1187-1199. http://dx.doi.org/10.1080/00103624.2011.566963

Mitchell, R., Vogel, K. P., \& Uden, D. R. (2012). The feasibility of switchgrass for biofuel production. Biofuels, 3(1), 47-59. http://dx.doi.org/10.4155/bfs.11.153

Mohan, D., Pittman Jr, C. U., Bricka, M., Smith, F., Yancey, B., Mohammad, J., . . Gong, H. (2007). Sorption of arsenic, cadmium, and lead by chars produced from fast pyrolysis of wood and bark during bio-oil production. Journal of Colloid and Interface Science, 310(1), 57-73. http://dx.doi.org/10.1016/j.jcis.2007.01.020

Novak, J. M., Lima, I., Xing, B., Gaskin, J. W., Steiner, C., Das, K. C., . . Schomberg, H. (2009). Characterization of designer biochar produced at different temperatures and their effects on a loamy sand. Annals of Environmental Science, 3, 195-206.

Pastorova, I., Botto, R. E., Arisz, P. W., \& Boon, J. J. (1994). Cellulose char structure: a combined analytical pyrolysis gas chromatography-mass spectrometry, FTIR, and NMR study. Carbohydrate Research, 262(1), 27-47. http://dx.doi.org/10.1016/0008-6215(94)84003-2

Perlack, R. D., Wright, L. L., Turhollow, A. F., Graham, R. L., Stokes, B. J., \& Erbach, D. C. (2005). Biomass as feedstock for a bioenergy and bioproducts industry: The technical feasibility of a billion-ton annual supply. Oak Ridge National Laboratory: United States Department of Energy.

Sarmah, A. K., Srinivasan, P., Smernik, R. J., Manley-Harris, M., Antal Jr, M. J., Downie, A., \& Van Zwieten, L. (2010). Retention capacity of biochar-amended New Zealand dairy farm soil for an estrogenic steroid hormone and its primary metabolite. Australian Journal of Soil Research, 48, 648-658.

Sun, J., Kang, X.-J., Ma, Y.-Q., Chen, L.-Q., Wang, Y., \& Gu, Z.-Z. (2011). The study of adsorption characteristics of electrospun polymer nanofibers for benzenes in water. Water Science and Technology, 64(2), 528-533. http://dx.doi.org/10.2166/wst.2011.529

Urraca, J. L., Marazuela, M. D., Merino, E. R., Orellana, G., \& Moreno-Bondi, M. C. (2006). Molecularly imprinted polymers with a streamlined mimic for zearalenone analysis. Journal of Chromatography A, 1116(1-2), 127-134. http://dx.doi.org/10.1016/j.chroma.2006.03.032

Vogel, K. P., Sarath, G., Saathoff, A. J., \& Mitchell, R. B. (2011). Switchgrass. RSC Energy Environ. Ser., 3, 341-380.

Whitehead, S. A., \& Rice, S. (2006). Endocrine-disrupting chemicals as modulators of sex steroid synthesis. Best Practice, \& Research Clinical Endocrinology \& Metabolism, 20(1), 45-61. http://dx.doi.org/10.1016/j.beem.2005.09.003

Widowati, Utomo, W. H., Guritno, B., \& Soehono, L. A. (2012). The effect of biochar on the growth and N fertilizer requirement of maize (Zea mays L.) in green house experiment. Journal of Agricultural Science, 4(5), 255-262. http://dx.doi.org/10.5539/jas.v4n5p255

Yoon, Y., Westerhoff, P., Snyder, S. A., \& Esparza, M. (2003). HPLC-fluorescence detection and adsorption of bisphenol A, 17 $\beta$ - estradiol, and 17 $\alpha$-ethynyl estradiol on powdered activated carbon. Water Research, 37(14), 3530-3537. http://dx.doi.org/10.1016/s0043-1354(03)00239-2

Zheng, W., Guo, M., Chow, T., Bennett, D. N., \& Rajagopalan, N. (2010). Sorption properties of greenwaste biochar for two triazine pesticides. Journal of Hazardous Materials, 181(1-3), 121-126. http://dx.doi.org/10.1016/j.jhazmat.2010.04.103 